\title{
DE LAS INDIAS A MADRID: LOS ESPACIOS DE LA DOROTE ${ }^{1}$
}

\author{
PATRICIA FESTINI \\ Universidad de Buenos Aires \\ Instituto de Filología y Literaturas Hispánicas «Dr. Amado Alonso» \\ pfestini@filo.uba.ar
}

$\mathrm{U}$

na de las escenas más recordadas de La Dorotea de Lope de Vega, y que funciona como cifra de toda la obra, es, sin duda, la del sueño présago de don Fernando, aquel en el que el mar llegaba de las Indias a Madrid:

FERNANDo [...] Soñaba, ;oh Julio!, que había llegado el mar hasta Madrid desde las Indias.

Julio Ahorrárase mucho porte desde Sevilla a Madrid. Di adelante.

FERNANDo Llegaba furioso hasta la puente [...]. En una famosa nave enramada de jarcias y vestida de velas, venía un hombre solo, que desde el corredor de popa arrojaba a una barca barras de plata y tejos de oro.

JULIO ¿Quién estuviera en la barca!

FERNANDo Estaba, ¡ay de mí! [...] Estaba Dorotea.

JULIO ¿Y tomaba el oro?

FERnANDo Con las dos manos. (33-34) ${ }^{2}$

A partir de este sueño simbólico, en el que la violencia del mar llega desde las Indias a la Corte, es posible perfilar algunos de los espacios de La Dorotea. El gran espacio ausente de las Indias, aunque presente en la obra por medio de alusiones y personajes: desde allí llega don Bela, allí está el marido de Dorotea y, sobre todo, desde las Indias llega el oro, que rige, en gran medida, el destino de

1 Este trabajo fue presentado en el Seminario Internacional sobre Literatura y Corte Prosas y versos de Lope de Vega en el Madrid Cortesano (Madrid, Universidad Autónoma de Madrid Instituto Universitario «La corte en Europa», 3 y 4 de abril de 2017).

2 Todas las citas del texto corresponden a Lope de Vega, La Dorotea, edición de Donald McGrady (2011).

Edad de Oro, XXXVI (2017), pp. 233-247, ISSN: 0212-042 - DOI http://dx.doi.org/10.15366/edadoro2017.36.013 
los protagonistas. Sevilla, apenas mencionada, será el lugar que don Fernando elija para olvidar a Dorotea. Por último, el espacio de Madrid, el espacio de la corte, que es donde transcurre la «acción en prosa».

Pero el estudio de La Dorotea presenta muchos otros espacios: el espacio de lo genérico, el espacio de la prosa, el espacio de la poesía, el espacio de la polémica. A alguno de esos espacios, no todos, quisiera referirme en este trabajo. Y también a cómo esos grandes espacios del sueño agorero de don Fernando se van reduciendo en función del experimento literario que el texto propone.

Publicada en 1632, La Dorotea resulta, al menos, una obra curiosa, una obra diferente dentro de la producción de Lope. Su autor la presenta como «acción en prosa», en parte perfilando esta suerte de hibridación entre comedia y novela, que es uno de los modos como se la caracteriza, y en parte, como señala Jaime Moll (1979), en un intento de burlar la prohibición que regía en Castilla para publicar novelas y comedias.

Anclada en lo que Juan Manuel Rozas (1990) definió como «ciclo de senectute», La Dorotea acarrea una fortuna crítica condicionada por sus circunstancias de enunciación y recepción a lo largo del tiempo. Por un lado, su interpretación en clave autobiográfica, derivada de lo que se ha dado en llamar la «materia Osorio», que reduce el texto a la recreación de un suceso de la juventud de Lope, reconstruido en esta oportunidad por el Lope anciano: sus amores con Elena Osorio y la aparición del pretendiente rico (Francisco Perrenot de Granvela), espejados aquí en el triángulo que forman Fernando, Dorotea y don Bela ${ }^{3}$.

Un segundo modo de aproximación al texto tiene que ver con su inserción en la tradición celestinesca, lo que resulta otra reducción, otra simplificación que se retrotrae a la afirmación de Menéndez Pelayo (1946: 238) de que «Lope de Vega tributó a la Celestina el más alto homenaje, imitándola con magistral pericia en aquella "acción en prosa", que era una de sus obras predilectas (por ventura de mi la más querida)», por lo que se condiciona la lectura del texto a verlo como una continuación de la Tragicomedia de Calisto y Melibea ${ }^{4}$.

Su pertenencia al «ciclo de senectute» del autor incorpora otros elementos que también fueron tenidos en cuenta por la crítica, como el desengaño que supuso la no obtención del cargo de cronista real, en favor de Pellicer, y que explicaría,

3 Excede los límites de este trabajo una revisión minuciosa de los numerosos aportes críticos que se han ocupado de La Dorotea, por lo que remito a la excelente edición de McGrady (2011), que ofrece un relevamiento bibliográfico actualizado.

4 En relación con su acercamiento a la celestinesca, resulta interesante la lectura de Manuel Piqueras Flores (2013: 56), quien, entre muchas otras líneas de análisis, se detiene en el género de la obra, a la que define como «tragicomedia definitiva», si bien señala que, «aunque mantiene más características propias del teatro que La Celestina, puede decirse también que es incluso menos teatral que la obra de Rojas, no por su configuración en sí, sino por el público al que estaba destinada», subrayando, además, su relación con «el género novelesco». 
también en clave autobiográfica, la sátira a los comentos que, a partir del análisis del soneto «Pululando de culto, Claudio amigo», nutre las escenas segunda y tercera del acto IV. Escenas que, a su vez, también dispararon múltiples lecturas dada su relación con la polémica gongorina, resignificada aquí a través de los dardos dedicados a los «pájaros nuevos» y a satirizar las Lecciones solemnes de Pellicer.

Como vemos, nos encontramos ante una obra cuya fortuna crítica es amplia pero también dispar. Ahora bien, ¿qué lugar ocupa dentro de este conglomerado crítico el análisis de los espacios de La Dorotea? Fernando Copello (2001: 41-42) considera que la antítesis funciona como principio estructurador de la obra y, desde allí, plantea una oposición en los espacios que presenta el texto, confrontando lo urbano y lo rural:

Lo urbano aparece en el escenario total de la obra, que transcurre en Madrid. El viaje de don Fernando a Sevilla no está representado, lo que explica la ausencia del poeta enamorado en el acto II, pero sabemos que don Fernando está en Sevilla y en Cádiz. Lo que caracteriza a estos personajes lopescos es lo ciudadano. Ahora bien, en esta vida que los protagonistas desean, en esa existencia ideal que haría de don Fernando y de Dorotea «personajes literarios», hay una ambición rural o más precisamente bucólica que se opone al universo cortesano.

De allí que el universo pastoril sea una constante en los versos de La Dorotea y que en ellos zagalas, pastores y serranas manifiesten, junto a arroyuelos y ríos, sus penas de amor.

Por su parte, Florencia Calvo toma como punto de partida el trabajo en el que Alban Forcione (1969) define la temporalidad en La Dorotea, como the broken clock, reloj roto, tiempo desarticulado que se corresponde con un manejo no cronológico de la temporalidad. Teniendo en cuenta esta aproximación, Calvo (2016: 9) se plantea la posibilidad de considerar un funcionamiento similar para la unidad de espacio:

[...] los espacios urbanos son, en su mayoría, rejas, calles, paseos al aire libre por el Prado, espacios en los que se deberían producir acciones propias de comedias urbanas o de novellas, espacios que deberían reglar y regular de manera ordenada el discurrir del relato. Sin embargo, esta espacialidad funciona del mismo modo descripto por Forcione para la temporalidad, es un espacio roto. Son espacios que se constituyen como índices genéricos en tanto son desbordados constantemente por la materia narrativa.

En este sentido, tanto la temporalidad como la espacialidad se entrecruzan en el modo en que se nos cuenta la historia.

Pensemos primero en los grandes espacios. Las Indias, ausentes, lejanas, pero unidas a Madrid por el mar del sueño y presentes metonímicamente en don Bela, 
el marido de Dorotea, y en el oro, que recorre el texto. Frente a las Indias, tenemos un Madrid presente: el Prado, la carrera de San Jerónimo, la iglesia de la Merced, la de Atocha..., espacios rotos en función de la trama pero que le dan un protagonismo a la ciudad. Es el Madrid de La Dorotea, con sus rejas y sus calles, pero también con el Prado como un centro en el que, cual comedia, cual novela, confluyen gran parte de los personajes y la historia toma un nuevo rumbo. Opuesto a él, el universo pastoril con el espacio de sus soledades.

Frente a estos grandes espacios, las calles, las rejas, pero también los interiores de las casas con detalles que conforman otros lugares desde donde se cuenta la historia de los amores de Fernando y Dorotea. Un recorrido por algunos momentos de la obra nos dará cuenta de cómo funcionan todos estos espacios en el marco de la «acción en prosa».

Las Indias llegan a La Dorotea en boca de Gerarda: «Yo he sabido que un caballero indiano bebe los vientos desde que la vio en los toros», caballero que está dispuesto a darle «una cadena de mil escudos con una joya» (24). La figura del indiano rico aparece así en el texto y provoca el enojo de Dorotea con su madre: « $i$ Notable batería hizo en el muro de tu entendimiento la fisionomía liberal del rico indiano!» (28); y también su lamento, en el primer soliloquio de la obra, al pensar en la pérdida de su amante: «¿qué Indias los podrán suplir, qué oro, qué diamantes?» (31). Tres pequeños momentos que preparan el sueño agorero de don Fernando: la figura de Dorotea bajando de la barca, cargada de oro, y que pasa ante él sin conocerlo.

De este modo, Indias y oro ingresan al texto como un espacio simbólico que va a provocar la ruptura entre Dorotea y don Fernando: «que la mar que esta noche he soñado me anegue y me sepulte, y el oro que te daban te conquiste» (44), dirá este ante la presencia de la dama. La pesadilla comienza a hacerse realidad, si bien Dorotea culpa a Teodora: «a un indiano me entrega. El oro la ha vencido» (48). Abrumado, ofendido, Fernando le dice que se vuelva a su casa, ya que no piensa volver a verla: «Porque te vas a las Indias, y hay mar en medio» (50). El sueño, así, toma forma y el espacio se vuelve distancia que separa a los amantes. Fernando se va a Sevilla y Dorotea intenta suicidarse, tragándose el diamante. Sin embargo, ya en el acto II, y con motivo de los celos que siente cuando Marfisa, fingiendo una visita casual, la pone al tanto de su relación con don Fernando, Dorotea decide rendirse «al indiano y a las Indias $\rangle^{5}$.

Las Indias se vuelven un elemento omnipresente, en principio, como espacio generador de la riqueza de don Bela, aunque luego, a lo largo del texto, van

Son las habladurías de Marfisa las que provocan la rendición de Dorotea: «Pues está cierta, Celia, que no he tenido primero movimiento de rendirme, ni al indiano ni a las Indias, hasta este punto en que he oído de boca desta dama traición tan grande» (102). 
cobrando nuevas significaciones. Veamos algunos ejemplos para aclarar estas cuestiones.

Don Bela aparece en el comienzo del acto II, afirmando que «todo el oro que el sol engendra en las dos Indias» le parece poco para recompensar a Gerarda, «y aunque se añadieran los diamantes de la China, las perlas del Mar del Sur y los rubíes de Ceilán» (80). A partir de allí, resultan interesantes las transformaciones que se operan en torno a este espacio simbólico. Para don Bela, Madrid se convertirá en las Indias ante la contemplación de Dorotea: «Nunca yo estuve más en las Indias, que mereciendo ver a Dorotea» (186), le dirá a Laurencio, cuando este cuestione su liberalidad con la dama. Don Bela se mueve en un espacio cíclico. Sale de las Indias, cargado de oro, y regresa a ellas por el oro, por la riqueza que significa poder tener a Dorotea.

Por su parte, para Fernando, las Indias son sinónimo de desdicha. Al sueño que se va haciendo realidad se suma el relato de infortunios pasados. Muertos sus padres, un abogado cobró lo que pudo y pasó a América dejando a don Fernando en la pobreza: «[...] que siempre fui desdichado en las Indias, pues como otros traen dellas hacienda, me llevaron allá la mía. [...] ¡Pluguiera al cielo que nunca se hubieran descubierto, ni Colón hubiera nacido en el mundo!» (256-257). En clara correspondencia con esta exclamación, Julio, frente al desmayo de Fernando en el Prado, le va a recetar la yerba Dorotea, «quitadas todas las hojas de las Indias» (276). Sin embargo, la receta hace efecto en ella:

Yo vi lágrimas en Fernando cuando más desconfiaba de su memoria. Será mío, aunque pese a esta vieja de mi madre y a la hechicera que la aconseja. No quiero Indias, ni cautivar mis años. ¿Qué oro, qué diamantes como mi gusto? (326)

Estos ejemplos son suficientes para dar cuenta de cómo se construye este espacio simbólico.

Sevilla también puede considerarse simbólicamente. Allí llega Fernando gracias al oro de Marfisa, oro que no viene de las Indias pero que permite el alejamiento. Frente a la ruptura con Dorotea, en el acto I, Fernando dirá: «Mejor es imaginar que soy muerto, y que mi alma sola es la que va a Sevilla», lo que provoca la pregunta de Julio: «¿Quién te ha dicho que las almas de los amantes ausentes van a Sevilla?» (61). Fernando no quiere permanecer en Madrid, para alejarse del peligro elige la ausencia. Y una vez más, el desarrollo de la «acción en prosa» retoma estos conceptos esparcidos. Así, en plena convalecencia, el pensamiento de Dorotea está puesto en don Fernando:

Dime que piensa en mí, revolviendo la memoria de nuestras cosas pasadas, [...] que va y viene desde Sevilla a Madrid más veces su imaginación que tiene el tiempo instantes; [...] (91) 
Fernando me quiso en Madrid, y me querrá en Sevilla. Y si se le olvidare, yo le enviaré allá mi alma que se lo acuerde. (94)

Frente a estos espacios simbólicos surge Madrid como el gran espacio en que transcurre La Dorotea, y frente a Madrid, los versos que remiten al universo pastoril. Analizar cómo se desarrollan las escenas en el espacio de Madrid excede los límites de este trabajo. Es por eso que, a partir de aquí, quiero proponer dos líneas de lectura. En principio, quisiera detenerme en algunas escenas significativas en la conjunción entre el espacio y el avance de la narración. Luego, para finalizar, me propongo rastrear cómo aparece Madrid como Corte en esta obra de Lope.

El que Madrid sea el gran espacio en que transcurre la «acción en prosa» está claro, pero también está claro que puede considerarse como un espacio roto y que, en la construcción de ese espacio, la comedia gana sobre la novela. Cuando se construye, cuando el lector no tiene que adivinar dónde transcurre la escena, se lo hace a través de didascalias implícitas, como en gran parte de la producción dramática del Fénix. Y no son muchas las oportunidades en los que el texto nos ofrece algún dato más sobre el espacio. Como en una comedia, las didascalias ${ }^{6}$ señalan la entrada y salida de personajes. A modo de ejemplo, revisemos las del acto I.

«Con esto me voy a rezar a la Merced» (25-26), dice Gerarda al finalizar la primera escena, para que, a continuación pero ya en la segunda, ingrese Dorotea a increpar a su madre. No nos tiene que sorprender esta hibridación, ya que la comedia está presente en boca de los personajes. Esta discusión la cierra Teodora diciendo «que no hago yo aquí papel de galán celoso, sino de madre honrada» (30)7.

Del mismo modo, al finalizar la escena cuarta, don Fernando anuncia la entrada de Dorotea en el comienzo de la siguiente con un «Paréceme que siento chapines», lo que provoca la respuesta de Julio: «Ese ruido y el de las cantimploras dicen es el mejor» (42). En la escena sexta, será Clara quien anuncie a Marfisa la llegada de don Fernando: «Él y Julio, su ayo o su perdición, vienen muy aprisa, y a la puerta se queda su amigo Ludovico» (65). Y, al final de la escena séptima, Teodora interroga a Gerarda sobre «cómo se ha de remediar Dorotea para el honesto tálamo» (74), para exclamar a continuación: «Gerarda, no paséis adelante, que ella y Celia están fuera, y pienso que vienen», y la tercera responde «Voyme por esotra puerta» (75). Así, el comienzo de la escena final está dado por las preguntas inquisidoras de Teodora: «¿De dónde vienes a las dos de la tarde, Dorotea? ¿Qué templo hay agora abierto? ¿Qué devoción te escusa?» (75).

$6 \quad$ En este sentido, se pueden aplicar aquí las reflexiones de Javier Rubiera sobre el espacio en la comedia española áurea cuando señala que, el lugar donde se desarrolla la acción, «el dramaturgo del siglo de oro no lo hace explícito al margen del diálogo sino en el interior del parlamento de los personajes (en didascalias)» (2005: 33).

7 Sobre el diálogo que desde La Dorotea Lope plantea con la comedia urbana pero también con las Novelas a Marcia Leonarda, véase Calvo 2016. 
Las didascalias implícitas, entonces, nos van a ubicar espacialmente en el lugar en el que se desarrolla la acción en prosa, pero también van a jugar un papel importante en el avance de la narración, como al final de este mismo acto primero, en el que un hipotético sonido desencadena la escena final:
Dorotea ¿Qué ruido es ese que hay en la calle?
Celia Unos caballeros que van de camino, y en el habla me parece que he conocido a Julio.
Dorotea El alma me has turbado: voy a verle. ¡Ay triste! Aquel de las plumas y la cadena, ¿no es don Fernando?
Celia Ahora vuelve el rostro.
Dorotea Él es sin duda, él se va por lo que le dije. ¿Cómo podré llamarle?
Celia No es posible, que va muy aprisa.
Dorotea ¡Qué coléricos son los celos! ¡Muerta soy! ¡Oh, qué mal hice! Mi Fer- nando se va, no quiero vida.
Celia ¿Qué haces, señora? ¿Qué has metido en la boca? ¡Jesús! La sortija de los diamantes se ha tragado para matarse. (76-77)

La interpretación del ruido motiva que Dorotea se trague la sortija. La didascalia que ubica a don Fernando en la calle da pie para la decisión de Dorotea, la que conocemos, dramáticamente hablando, a través de otra didascalia implícita. $\mathrm{Al}$ estar el texto concebido como una «acción en prosa», son necesarias estas acotaciones que complementan el entramado narrativo. Estas son los elementos que nos van a guiar por calles, rejas, ventanas, la habitación de Fernando, el estrado de Dorotea. Algunas veces, la construcción del espacio se complementa en una narración posterior, como, por ejemplo, cuando Ludovico describe los cambios en la casa de Dorotea: «Últimamente yo fui a visitarla ocho días antes que vos viniésedes [...]. Hallé una rica tapicería y estrado nuevo» (198).

Un capítulo aparte merece el Prado como espacio. En esa misma conversación con Ludovico, Fernando le cuenta: «Al alba salgo al Prado, o me voy al río, donde sentado en su orilla estoy mirando el agua, dándole imaginaciones que lleve, para que nunca vuelvan» (202). El comentario, que remite en parte al universo pastoril, anuncia los paseos de Fernando por el Prado. No olvidemos que era uno de los paseos favoritos de la época y que, ya en el primer acto, el sueño agorero de Fernando motiva que Julio considere que, si arrojaban oro de los barcos, saldrían las mujeres a la mar de Madrid «más que al Prado» (34). El acto cuarto comienza con una nueva didascalia implícita, esta vez en boca de Marfisa, que exclama « $Q$ Qué solo está el Prado!», para que Clara le responda: «¿Cómo no quieres que lo esté, si apenas le acompaña el día?» (250). Las palabras de las dos mujeres nos ubican temporal y espacialmente. Primero, asistimos al encuentro de Marfisa con Dorotea. Un encuentro casual, trivial, que funciona como preámbulo de un segundo encuentro: el de Dorotea con Fernando. 
La escena difiere del resto de la obra porque incluye una suerte de novela enmarcada que, dentro de la totalidad de La Dorotea, completa la biografía del protagonista ${ }^{8}$. El narrador de esta novela es Fernando; los narratarios, Julio, Felipa y una embozada Dorotea que escucha el relato de la historia de su amante y, por lo tanto, el relato de su propia historia: «Yo, señoras, la que habla y la que no habla, nací de padres nobles en este lugar, a quien dejaron los suyos poca renta» (255). Así comienza la narración de don Fernando con una técnica muy común en la novela corta que Michel Moner (1986), refiriéndose a la narrativa cervantina, define como «relato curricular».

La historia amorosa, la historia de amor de don Fernando primero con Marfisa y luego con Dorotea, se desarrolla a lo largo de gran parte de la escena. El encuadre del relato está dado por el encuentro entre el par que forman Fernando y Julio frente a Felipa y Dorotea. Los hombres no conocen a Felipa, Dorotea está tapada, pero al finalizar la narración ella no soporta más la situación y se muestra ante don Fernando. Finalizada esta escena, cuya localización espacial es el Prado, los amantes vuelven a unirse mientras los lectores asistimos a un nuevo espacio. El espacio de la academia, el espacio de ese cenáculo literario en el que Ludovico, César y Julio comentan el soneto «Pululando de culto, Claudio amigo», en lo que se considera un eslabón más dentro de la polémica surgida en torno a la aparición del Polifemo y las Soledades de Góngora.

La extensa narración que don Fernando hace en esa primera escena del acto cuarto propone el desarrollo de un hilo narrativo dentro de la estructura y el contenido in medias res de la acción en prosa. El lector repone así elementos importantes en la historia de los amantes. Pero la obra presenta otros momentos semejantes en los cuales, a través de la voz de uno de los personajes, es posible completar ese hilo narrativo que nos va a llevar al final de la historia de don Fernando, Marfisa y Dorotea. En función del tema que aquí nos ocupa, nos vamos a detener en la escena tercera del acto quinto. Allí, César y Julio asisten al relato de lo que podríamos llamar un nuevo capítulo de los amores entre Fernando y Dorotea.

El punto de partida es la referencia al encuentro de ambos amantes: «Ya supistes, señor César, [...] lo que os referí a vos y a Ludovico que me había sucedido en el Prado una mañana de abril pasado con Dorotea» (354). El relato intercalado nos remite a la escena del Prado, aunque solo figura como una introducción para insertar el nudo de esta nueva narración: el fin del amor de don Fernando:

FERnANDo [...] Apenas, César, conocí que Dorotea me tenía el mismo amor que antes que me partiese a Sevilla, cuando comenzó mi espíritu a sosegarse, mi corazón a suspenderse, y todas las acciones de hombre cuerdo y prudente volvieron a la patria del entendimiento, de donde las había desterrado la inquie-

$8 \quad$ Sobre la consideración del relato de don Fernando como una novela corta, véase Festini (2017). 
tud de imaginarme aborrecido. [...] Al paso, finalmente, que Dorotea me iba descubriendo su pecho, iba yo sosegando el mío, y como se abrasaba en mis brazos de aquellos antiguos deseos, yo me helaba en los suyos. (354)

Fernando continúa con la historia de sus amores, con el relato de su relación con Marfisa en un nuevo salto hacia ese pasado no contemplado por la acción en prosa. También se refiere a los celos provocados por la presencia de don Bela, al intercambio de billetes amorosos a través de la reja, con hábito de pobre, y cómo, a partir de una camisa que Marfisa le regala, como en una comedia de enredo, se truecan los papeles y Dorotea conoce que ya no es la única en el corazón de don Fernando.

Luego del relato intercalado, el Prado vuelve a ser mencionado antes de que finalice la escena. Esta vez para dar cuenta de un elemento que le otorga a la «acción en prosa» un anclaje histórico-temporal importante. La referencia a una boda que tuvo lugar en Barcelona a fines de 1587, y cuya celebración continuó en Madrid en enero de 1588, motivo por el cual César escribió un epigrama9:

CÉSAR A mi posada voy, y si no viniere a la tarde a veros, vendré mañana. Porque tengo que llevar un epigrama que he escrito a los felicísimos casamientos de la excelentísima señora doña Vitoria Colona y el conde de Melgar, hijo del gran almirante de Castilla, don Luis Enríquez de Cabrera; que como sabéis, entró ayer en esta Corte, donde fue recibida con tanto aplauso, que no se ha visto en Madrid más alegre día, ni más lucido de galas. Era el Prado un jardín de caballeros y damas [...]. (367)

De todos los espacios que aparecen mencionados en La Dorotea, el Prado es el único que puede identificarse con exactitud y en el que se desarrolla una escena importante para el avance de la acción en prosa. Las iglesias también son lugares identificables, pero solo aparecen nombradas para dar cuenta de idas y venidas de los personajes, ajenas al desarrollo de la acción. El hecho de que el Prado sea el elegido para darle el encuadre al relato de una historia que comienza in medias res y que, a partir de allí, puede rearmarse ab initio, lo destaca como un espacio importante dentro de la obra. Si además tenemos en cuenta que el relato de don Fernando puede considerarse una novela enmarcada, qué mejor espacio para narrarla que un jardín, lo que puede relacionarse con el itinerario que la ficción recorrió desde el Decamerón de Boccaccio hasta las primeras décadas del siglo XVII, en el que siempre se priorizaron los jardines como un sitio ideal para contar historias.

\footnotetext{
9 «Estos "felicísimos casamientos" se celebraron en Vic (al norte de Barcelona) el 31 de diciembre de 1587, y después los participantes siguieron a Madrid; por consiguiente, la presente escena se sitúa en enero de 1588» (McGrady 2011: 367, nota).
} 
En relación con la «acción en prosa», el Prado cobra protagonismo al permitir el encuentro de los amantes y sellar su retorno, aunque esto, obviamente, fuera de sus jardines:

Julio Gente viene al Prado. Mejor es que nos vamos juntos, que en nuestra casa podéis hablar sin que os juzguen, y averiguar estas quejas sin testigos.

DoroteA Si Fernando me da la mano, yo iré con él. Si no, ten por sin remedio que tengo de dar mil voces y hacer mil locuras en este Prado.

Julio ¡Ea, reyes míos!, que en el Prado y por abril solo tienen licencia los rocines. (279)

Protagonismo que se acentúa aún más, ya que el reencuentro, como vimos, significó el comienzo del fin de los amores de don Fernando, quien toma como punto de partida para anunciarlo lo sucedido en el Prado. En ese sentido, no parece casual que, como cierre de la historia de los amores entre Fernando y Dorotea, el Prado sea el escenario de la celebración de la boda de doña Vitoria Colona, inmortalizada en el epigrama de César que finaliza con el «Será Coluna de inmortal Vitoria» (369) y que nos conduce al Madrid cortesano.

Pero antes de centrarnos en cómo aparece la Corte en La Dorotea, quisiera ocuparme de un último espacio en este recorrido por los lugares de la obra. Es un espacio pequeño que aparece tras las rupturas, tras las ausencias.

En la mayor parte de las novelas del siglo XVII español, los microtextos cumplen un papel estructurante ${ }^{10}$. Los versos y papeles que se entrecruzan los enamorados son fundamentales en el avance de la narración. En La Dorotea, en cambio, la utilización de microtextos se resignifica, y o remiten a momentos pasados o son verdaderos interludios líricos, «porque descanse quien leyere en ellos de la continuación de la prosa» (8), como se nos promete en el Prólogo al Teatro, pues no aportan demasiado al desarrollo de la acción. De allí que la crítica señale que «las poesías de La Dorotea escritas tras la muerte de Marta-Amarilis sustituyeron a otras que el Fénix ya había dispuesto para la obra» (Brito Díaz 2003: 110), explicando la inserción de las cuatro barquillas ${ }^{11}$.

De toda la masa de papeles esparcidos a lo largo de La Dorotea, es posible rescatar algunos microtextos, ya sean cartas, ya sean versos, incluso retratos, que

10 Evangelina Rodríguez Cuadros, en una tesis sobre la novela corta del siglo XVII, se refiere a la inclusión de billetes amorosos e intermedios líricos, a los que denomina subtextos o microtextos, destacando su importancia estructural en relación con la «dinámica generante de conflictos, resolución o creación de relaciones tensionales» (1979: 148).

11 Tengamos en cuenta que Marta de Nevares murió el 7 de abril de 1632, un mes antes de las aprobaciones de la obra, que datan del 6 de mayo. 
ocupan el pequeño espacio de los escritorios y que evocan algunos momentos de la relación entre los amantes, previos a la ruptura.

Del escritorio de Fernando salen los papeles que el galán relee cuando decide marcharse a Sevilla:

Julio $\quad[. .$.$] ¿Qué andas en ese escritorio? ¿Qué buscas? ¿Qué rasgas? Deja$ los papeles, deja el retrato. ¿Qué te ha hecho esa divina pintura? Respeta en ese naipe los pinceles del famoso Felipe de Liaño [...]. (53)

Son poemas, el retrato de Dorotea y una carta, en la que le recrimina el haberle dado una bofetada. Cada papel que surge del escritorio dispara el recuerdo, motiva la nostalgia. «Escucha este» (55), dice Fernando, o «Este papel es de mi letra. Versos son. Ya me acuerdo, que me los volvió para que los cantase. Quiero leerlos» (56). Del escritorio salen los recuerdos que agravan la ausencia. Sabemos que no rompió el retrato porque alude a su entierro en el mencionado relato que hace en el Prado. Por el retrato de Fernando, nos hallamos ante otro escritorio, el «escritorcillo de los embustes» (99), como lo llama Dorotea. El lugar en el que, entre otros papeles, guarda el retrato, pintado también por Felipe de Liaño, que le muestra a Marfisa.

Volvemos a encontrar el escritorcillo en la escena cuarta del último acto. Exactamente, a continuación del anuncio que hace don Fernando del fin de sus amores con Dorotea, y asistimos a un diálogo similar al que mantuvieron Julio y Fernando en el primer acto, desarrollado aquí entre la joven y Gerarda:

GERARDA ¿En qué andas? ¿Qué sacas dese escritorio? Parece retrato. ¿Mas que sé de quién es? Muestra, muestra.

DoroteA Luego le verás, Gerarda. Ve ahora, por tu vida, y consuela a mi madre que está llorando de verme triste [...]. (373)

La escena concluye con un largo soliloquio de Dorotea, del que rescato algunos fragmentos:

DoRoteA $[\ldots]$ ¿Qué me miráis con aquella falsa risa que os puso Felipe en esos ojos? ¿Qué decís? ¿Por qué no habláis? [...] Aquí dice: «Esclavo de Dorotea». Esclavo no, fugitivo sí. [...] ¡Oh quién pudiera, como romper este retrato, hacer en el del alma el mismo castigo! ¡Jesús, que fuerte se hace! Pues, perro, ¿tú te resistes? Pero no, que mi flaqueza es la que no tiene fuerza para romperle, porque lo intento con las manos de amor, y Amor es niño. Desta vez lo rompo; quiero volver los ojos a otra parte. Rompile. ¡Vitoria! Lo mismo hará con su ejemplo del que tengo en el alma. ¡Celia, Celia! (373-374) 
Así termina la escena cuarta. La quinta comienza casi del mismo modo. Al ingreso de Celia, Dorotea exclama: « $i$ Vitoria, vitoria! Rompí el retrato de don Fernando» (374).

¿Coincidencia, casualidad? El grito de victoria de Dorotea es demasiado cercano en el texto al final del epigrama de César, «Será Coluna de inmortal Vitoria». El triunfo de la unión en la boda cortesana; el triunfo de Dorotea frente al desdén de don Fernando, triunfo porque no solo se contenta con romper el retrato y rasgar los papeles. Como Fernando, los toma, los lee, recuerda, pero finalmente, los quema:

Dorotea «Amaneció el alba, y no a mis ojos. Y díjele yo que ¿para qué salía?» Celia No leas esas boberías [...].

Dorotea Vaya al fuego [...]. Hoy dice Felipe de Liaño que irá a retratarte, y yo le digo que ¿dónde ha de hallar colores?» [...] Ay Celia, ¿esto me parecía bien entonces? ¿Qué estrañas necedades! Vaya al fuego.

Celia Vaya. Pero está cierta, señora, que no hay cosa que más necia parezca que un papel de amores fuera de la ocasión, o acabado el juego. Mas así Dios te guarde, que los quememos juntos [...]. (378-379)

En el incendio, se desintegran los últimos vestigios de los amores de Fernando y Dorotea. No alcanza con romperlos. Se deben destruir. El pequeño espacio del escritorcillo de los embustes conservó, hasta casi el final de la historia de los amantes, esos papeles que representaban el pasado ya ausente. Frente a la ruptura, el espacio ya no es necesario porque su contenido se convierte en cenizas, en humo, en nada. "Aquí dio fin la historia» (380), dirá Dorotea, casi como epitafio por la muerte de sus amores.

Hasta aquí, el análisis -no exhaustivo- del tratamiento de los espacios en $L a$ Dorotea en relación con el desarrollo de la «acción en prosa». Los grandes espacios se reducen hasta este espacio mínimo en el que se desintegran los últimos vestigios de la historia de los amantes. Las didascalias implícitas le brindan al texto cierto dinamismo de comedia, a la vez que contribuyen a anclar espacialmente momentos en los que, desde la palabra de los personajes, parece construirse una novela, acentuando la hibridez de uno de los últimos experimentos literarios de Lope.

Por último, nos detendremos en un último espacio: el de Madrid como Corte, con toda la connotación negativa que tenía en la literatura de la época.

La presencia de la Corte en el texto es bastante sutil. No encontramos aquí grandes discursos en contra de sus personajes y costumbres. Sí aparece aludida en algunos diálogos. Gerarda, en la primera escena del primer acto, le recriminará a Teodora que, si hubiese reñido a Dorotea, «no os murmuraran vuestras vecinas, y tuviérades mejor opinión en la Corte» (20). Será Gerarda también la que cuestione la actitud de Dorotea ante un obsequio de don Bela: «Acaba, muchacha. ¿Qué 
rehúyes los dedos? ¡Qué descortesía! ¿Tú naciste en la Corte?» (128). Por su parte, Fernando, al contar su historia, menciona que Dorotea rompe con él porque su madre y deudos la afrentaban y que los dos ya eran «fábula de la Corte» (265).

Distinto es el caso de Laurencio y don Bela. El criado le recrimina a su amo tanta liberalidad. El indiano le responde «Yo me conozco», pero Laurencio replica «Y yo la Corte» (88). Lo cierto es que don Bela parecía estar preparado para la Corte, de allí el simpático «Arancel con que ha de andar un caballero indiano en la Corte» (113), que le quita Gerarda. En relación con la caracterización tradicional del indiano, la mayoría de las reglas de este arancel aconseja la economía. Sin embargo, hay algunos elementos que responden a la sátira cortesana como «No se enamore, que en la Corte lo que se alcanza nunca fue de uno solo», «En viendo que murmuran, diga que tiene que hacer, y váyase», o «No se acueste sin haber dicho o hecho alguna lisonja donde pretende, que es la doctrina cortesana» (114).

En teoría, aquí terminaría nuestra revisión de la presencia de la Corte en $L a$ Dorotea. ¿Es así realmente?

El texto nos ofrece una clave para desentrañar un poema en el que se satirizan las miserias del Madrid cortesano. Un texto por el que desfilan caballeros mezquinos y aprovechados, falsos, presuntuosos, busconas, catarriberas, en donde el mundo al revés se manifiesta con jurisconsultos que toman las armas y soldados que frecuentan libros de derecho, malas intenciones, mala voluntad, todo en el marco de la suciedad de las calles de la ciudad. Como nos recuerda Julio, «dijo don Luis de Góngora de las calles de Madrid que eran lodos con perejil y yerbabuena» (224-225). La sátira no viene del madrileño, la sátira a la Corte llega de su archienemigo cordobés ${ }^{12}$, desde este verso que pertenece al soneto que elijo para terminar este recorrido por los espacios en La Dorotea ${ }^{13}$ :

Grandes, más que elefantes y que abadas,

títulos liberales como rocas,

gentileshombres, solo de sus bocas,

illustri cavaglier, llaves doradas;

hábitos, capas, digo, remendadas,

damas de haz y envés, viudas sin tocas,

carrozas de ocho bestias, y aun son pocas

12 También a través de un verso de Góngora, se satiriza el Manzanares en un diálogo entre Celia y Dorotea, mientras don Fernando está en Sevilla: «¿Pensabas que era el Betis como nuestro Manzanares, río con mal piedra, todo arenas, por quien dijo don Luis de Góngora, aquel famoso cordobés, que un jumento le orinó el invierno, y otro se le bebió el verano?» (95). El verso, mal citado («Bebiome un asno ayer, y hoy me ha meado»), pertenece al soneto «Duélete de esa puente, Manzanares», de 1588 (soneto 71 de la edición de Carreira 2016), en el que Madrid aparece nombrada por primera vez en la obra de Góngora.

13 Se trata del soneto número 69 de la edición de Carreira (2016), también del año 1588, como el ya citado sobre el Manzanares, gestados, probablemente, en el mismo viaje a la Corte. 
con las que tiran y que son tiradas; catarriberas, ánimas en pena; con Bártulos y Abades la milicia, y los derechos con espada y daga; casas y pechos, todo a la malicia, lodos con perejil y hierbabuena: esto es la corte; buena pro les haga.

\section{BIBLIOGRAFÍA CITADA}

Brito DíAz, Carlos (2003). «Lope en Lope: los palimpsestos del Fénix en su propia escritura (La Dorotea)». La Perinola: Revista de investigación quevediana, 7, pp. 103-122.

Calvo, Florencia (2016). «La Dorotea de Lope de Vega. Una cartografía de la inacción». Hesperia. Anuario de Filología Hispánica, 19-1, pp. 5-25.

Copello, Fernando (2001). «La Dorotea como género abierto». En Monique Güell (dir.), La Dorotea. Lope de Vega, Paris: Ellipses, pp. 37-51.

Festini, Patricia (2017). «La ciencia de La Dorotea: apuntes de poética a la luz del Prólogo al Teatro». Olivar, vol. 18, 27 (en prensa).

Forcione, Alban (1969). «Lope's broken clock: baroque time in The Dorotea». Hispanic Review, 37, pp. 459-490.

Góngora, Luis de (2016). Poesía. Antonio Carreño (ed.). [En línea]. Mercedes Blanco (dir.), «Édition digitale et étude de la polémique autour de Góngora». http://obvil.paris-sorbonne.fr/corpus/gongora/gongora obra-poetica/ [consulta: 15-08-2017]

MenÉndez Pelayo, Marcelino (1946). Orígenes de la novela, vol. 3. Buenos Aires: Espasa Calpe.

Moll, Jaime (1979). «¿Por qué escribió Lope La Dorotea?» Anuario de la Sociedad Española de Literatura General y Comparada, 2, pp. 7-11.

MONER, Michel (1986). «El "relato curricular": algunos aspectos de la narrativa cervantina». En Yves-René Fonquerne y Aurora Egido (coords.), Formas breves del relato. Zaragoza: Universidad, pp. 167-176.

PIQUERAS Flores, Manuel (2013). «La Dorotea, tragicomedia definitiva». Voz y Letra, vol. 24, 1, pp. 44-58.

RodríGuez CuAdros, Evangelina (1979). Novela corta marginada del siglo XVII español. Formulación y sociología en José Camerino y Andrés del Prado. Valencia: Universidad.

Rozas, Juan Manuel (1990). Estudios sobre Lope de Vega. Madrid: Cátedra.

RUBIERA FERNÁNDEZ, Javier (2005). La construcción del espacio en la comedia española del Siglo de Oro. Madrid: Arco/Libros.

Vega, Lope de (2011). La Dorotea. Edición, estudio y notas de Donald McGrady. Madrid: Real Academia Española. 


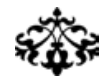

De las Indias a Madrid: los espacios de La Dorotea

RESUMEN: El presente artículo analiza la función de los espacios en La Dorotea de Lope de Vega, a partir del sueño présago de don Fernando (I, 4): las Indias, Sevilla y Madrid. Frente a las Indias y a Sevilla como espacios simbólicos, Madrid surge como el gran espacio en el que transcurre la «acción en prosa». La Corte, con sus iglesias, sus calles y sus rejas, pero también con el Prado como un centro en el que confluyen gran parte de los personajes y desde donde la historia toma un nuevo rumbo.

Palabras ClaVE: Lope de Vega, La Dorotea, espacio, novela barroca, comedia áurea.

\section{FROM THE INDIES TO MADRID: THE SPACES OF LA DOROTEA}

ABSTRACT: This article analyzes the role of the spaces in La Dorotea by Lope de Vega, from the presage dream of Don Fernando (I, 4): the Indies, Seville and Madrid. Facing the Indies and Seville as symbolic spaces, Madrid raises as the great space where the "action in prose» takes place. The Court, with its churches, its streets and its window bars, but also with the Prado as a center where many of the characters meet and where the story takes a new direction.

KEYWORDS: Lope de Vega, La Dorotea, space, baroque novel, golden comedy. 


\section{EDAD DE ORO}

Revista de Filología Hispánica XXXVI

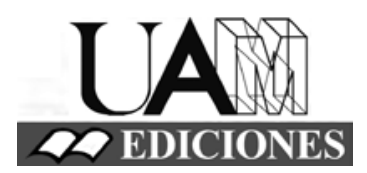




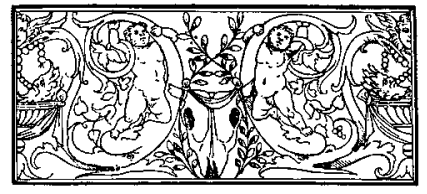

\section{Edad de Oro. Revista de Filología Hispánica}

ISSN: 0212-0429

Dirección:

Teodosio Fernández

Secretaría y edición:

José Ramón Trujillo

Consejo de redacción:

Manuel Piqueras

Blanca Santos

Admisión de originales:

María Jesús Zamora

Edad de Oro

Departamento de Filología Española

Universidad Autónoma de Madrid

28049 Madrid (España)

Tfno.: +0034914974090

correo: mariajesus.zamora@uam.es

Distribución, suscripción y venta:

Servicio de Publicaciones de la UAM

Universidad Autónoma de Madrid

28049 Madrid (España)

Intercambio de publicaciones:

Biblioteca de la Facultad de Filosofía y

Letras (UAM)

Universidad Autónoma de Madrid

28049 Madrid (España)
Comité científico internacional:

Carlos Alvar (Univ. de Ginebra)

Ignacio Arellano (Univ. de Navarra)

Javier Blasco (Univ. de Valladolid)

Alberto Blecua (UAB)

Jean Canavaggio (Univ. de París X)

Laura Dolfi (Univ. de Turín)

Aurora Egido (Univ. de Zaragoza)

Víctor García de la Concha (RAE)

Luciano García Lorenzo (CSIC)

Joaquín González Cuenca (Univ. de

Castilla-La Mancha)

Agustín de La Granja (Univ. de Granada)

Begoña López Bueno (Univ. de Sevilla)

Michel Moner (Univ. de Toulouse III)

Joan Oleza (Univ. de Valencia)

Alfonso Rey (Univ. de Santiago)

Lina Rodríguez Cacho (Univ. de Salamanca)

Leonardo Romero Tobar (Univ. de Zaragoza)

Aldo Ruffinatto (Univ. de Turín)

Lía Schwartz (City University of New York)

Han colaborado en este volumen:

Departamento de Filología Española (UAM)

Facultad de Filosofía y Letras (UAM)

Edad de Oro se recoge, entre otras, en las siguientes bases de datos: SCOPUS, MLA Database, HLAS, Latindex, PIO-Periodical Content Index, ISOC, Dialnet, MIAR, ERIH Plus, DICE, Sumaris CBUC, Ulrich's. Se encuentra evaluada en CIRC: A; MIAR difusión ICDS live 2016: 10.0; INRECH; SCImago Journal \& Country Rank: H Index 3, SJR SCImago Journal \& Country Rank 0,1, Q4; RESH índice de impacto: 0.041; ERIH: A INT1; Carhus Plus+2014: C. 